\title{
Do Contrato ao Status: as Terras Indígenas e o Supremo Tribunal Federal
}

\author{
Andressa Lewandowski ${ }^{1}$ \\ ${ }^{1}$ Universidade da Integração Internacional da Lusofonia Afro-Brasileira, \\ Redenção, CE, Brasil
}




\section{Resumo}

$\mathrm{O}$ artigo tem por objetivo discutir a noção constitucional de terra tradicionalmente ocupada, a partir dos fundamentos jurídicos, antropológicos e indígenas nos quais se ancoram os processos de demarcação de terras indígenas, explorando os limites das intepretações recentes em torno do conceito.

Palavras-chave: Terras Indígenas. Direito. Política.

\section{Abstract}

The article aims to discuss the constitutional notion of land traditionally occupied from the juridical, anthropological and indigenous foundations in which indigenous land demarcation processes are anchored, exploring the limits of recent interpretations around the concept.

Keywords: Law. Indigenous Land. Politics. 


\section{Introdução}

Ta entrada no Supremo Tribunal Federal em Brasília, vários 1 indígenas com bandeiras e chocalhos em punho. No salão do plenário, os ternos e gravatas deram lugar às pinturas corporais sob camisetas e colares. Mais de cem indígenas foram "autorizados" a assistir ao julgamento de dois dos inúmeros processos que circulam pelo tribunal, questionando as demarcações de terras. Nesse julgamento específico, em agosto de 2017, estavam em questão três Ações Civis Públicas (uma delas retirada da pauta pouco antes do julgamento), referentes a duas demarcações no estado do Mato Grosso. Além dos índios, a assistência do plenário da corte foi tomada por antropólogos e indigenistas, que mesmo vestidos de "advogados" dão um colorido diferente ao julgamento. Enquanto os antropólogos e indigenistas conversam e procuram lugares no plenário lotado, grande parte dos índios presentes permanece em silêncio. Dentro do salão do plenário não é possível ouvir os cantos entoados por outra centena de índios do lado de fora, na frente do tribunal, em vigília desde a noite anterior.

Quando o sinal do plenário tocou avisando que iriam entrar os ministros, um caiapó, sentado logo atrás de mim, me mostra uma pedra pequena e amarronzada; ele a tira do bolso e me diz que assim que os juízes entrarem, vai colocá-la em baixo da língua - um ritual de boa sorte, talvez. Na mesa de um dos ministros, cuja poltrona está logo à minha frente, também existe uma pedra, um cristal que acompanha uma cópia da Constituição Federal. O caiapó me conta rapidamente que é a primeira vez que entra em um tribunal, que o considera bonito, mas que está preocupado com sua comunidade. A decisão de um julgamento como esse pode atingi-los como uma bala - pelo 
menos desde a decisão desse mesmo tribunal em relação à demarcação contínua da Terra Indígena Raposa Serra do Sol, em 2007; decisão que não pôde ser comemorada como esperado, já que a demarcação contínua - reivindicação do povo indígena - veio acompanhada de 19 condicionantes. Desde então a atenção às decisões do STF é redobrada. A mobilização em torno dos ministros tenta evitar o prolongamento dessas condicionantes aos demais processos, evitando os riscos da paralização dos procedimentos de demarcação e da exclusão de várias comunidades de seu direito à terra ${ }^{1}$.

É sobre o STF e as terras indígenas que este artigo pretende se debruçar. Antes, darei um passo atrás, retomando o desafio apresentado pelo projeto “T/terras indígenas e territórios conceituais: incursões etnográficas e controvérsias públicas", do qual o presente artigo é tributário, cujo objetivo consiste em “[...] contribuir para a construção de uma interpretação antropológica que permita intervir no debate público recente em torno da noção de 'terra tradicionalmente ocupada', tal como consta no caput e no § 1 do artigo 231 da Constituição Federal" (Coelho de Souza et al., 2017, p. 2). No escopo do projeto está a reflexão que tenta articular os modos de viver e de constituir a terra dos diversos povos indígenas à necessidade de tornar essa terra reconhecível, ainda que parcialmente, pelo ponto de vista do direito. Reflexões semelhantes já apareceram nos trabalhos de vários antropólogos (Oliveira Filho, 1994; Gallois, 2004; Barreto Filho, 2005; Carneiro da Cunha, 2012), mas o recorte aqui proposto é especificamente o da relação entre terra e direito, tradicionalidade e efetividade.

A renovação do interesse na noção de "terra tradicionalmente ocupada" conecta-se também a uma conjuntura política de ofensiva contra os direitos territoriais indígenas e de outras comunidades tradicionais (Bonilla; Capiberibe, 2015). Nesse cenário cada vez mais desfavorável, se é que de algum momento na história se possa dizer o contrário, os grupos econômicos ligados ao agronegócio ganham um espaço ainda maior na política nacional, articulando projetos de emendas à Constituição que restringem o alcance do artigo constitucional 231. Pouca coisa parece conseguir frear o ímpeto desenvolvimentista de domínio do espaço, para o qual os povos e comunidades tradicionais não são senão um entrave. 
Nem mesmo os antropólogos ficaram imunes à força dos representantes da monocultura da soja e da pecuária bovina, vide a violência com que se tentou desqualificá-los durante a Comissão Parlamentar do Inquérito ${ }^{2}$, que investigou alguns dos processos administrativos de demarcação de terras indígenas e quilombolas. O que parece ter restado como arma contra a política genocida do Estado (Molina, 2017) é o texto do artigo 231 da Constituição Federal, lido integralmente por um dos ministros durante o julgamento, o que provocou um certo alívio na plateia: ele ainda está em vigor e é sobre ele que se fundamenta o direito à terra dos povos indígenas:

Art. 231 São reconhecidos aos índios sua organização social, costumes, línguas, crenças e tradições, e os direitos originários sobre as terras que tradicionalmente ocupam, competindo à União demarcá-las, proteger e fazer respeitar todos os seus bens.

$\S 1^{\circ}$ São terras tradicionalmente ocupadas pelos índios as por eles habitadas em caráter permanente, as utilizadas para suas atividades produtivas, as imprescindíveis à preservação dos recursos ambientais necessários a seu bem-estar e as necessárias à sua reprodução física e cultural, segundo seus usos, costumes e tradições.

$\S 2^{\circ}$ As terras tradicionalmente ocupadas pelos índios destinam-se a sua posse permanente, cabendo-lhes o usufruto exclusivo das riquezas do solo, dos rios e dos lagos nelas existentes. (Brasil, 1988, art. 231)

O capítulo em questão tem um nome que me parece importante ressaltar: "Dos Índios". Importante na medida em que esse capítulo, endereçado às etnias indígenas no Brasil, afirma justamente seu direito fundamental, o direito à terra. Diante dos ataques a esses direitos, que possibilita a vida dos povos indígenas, afirmar a vitalidade do dispositivo constitucional visando alcançar a radicalidade da expressão "segundo seus usos costumes e tradições" parece estar na ordem do dia, tanto para as organizações indígenas como para antropólogos e indigenistas, e por que não dizer, para os juristas e ministros do STF. É justamente essa a reflexão proposta pelo projeto T/terra e é uma parte dela que pretendo aqui retomar. 
Ao reativar as palavras do o texto constitucional não se pretende apagar o processo de produção que resultou neste artigo da Constituição, tampouco seus limites epistêmicos e políticos (para não dizer ontológicos), mas se trata, sobretudo, de situar o texto legislativo na história dos povos indígenas, desdobrando os sentidos diferenciados de seus direitos, para ressaltar a qualidade sui generis de uma terra indígena e de seu sujeito de direito, as comunidades indígenas no Brasil, e, sobretudo, para reafirmar a vitória de direito que a Constituinte representou para esses povos, as "conquistas" do artigo 231, que coloca o ponto de vista dos índios na aferição e na constituição da tradicionalidade e que garante a eles uma posição especial de cidadania envolvida em sua diferença.

O Supremo compõe essa reflexão na medida em que é, e tem se tornado cada vez mais, um agente fundamental no debate público, ora porque suas decisões têm aberto espaço no debate político em torno da efetivação do artigo 231, potencializando posições que restringem o alcance espaço-temporal do dispositivo legal, ora porque, ao reafirmar a diferença entre a sociedade nacional e os povos indígenas, acabam por criar uma imagem da terra indígena e dos índios que as ocupam tradicionalmente pouco permeável às experiências concretas do viver na terra para esses povos. Essas duas posições em torno da questão territorial indígena oscilam a cada julgamento e é sobre elas que vou me concentrar.

Se a judicialização é uma tendência incontornável, se a cada processo julgado um novo parâmetro do que é ou deve ser uma "terra tradicionalmente ocupada" pode ser estabelecido, cabe-nos insistir nesse debate. Nesse sentido, apresento este texto como um tipo de experimento, que certamente não é novo, tanto para mim, acostumada a pensar o direito pelas formas jurídicas que movimentam os conteúdos das decisões no Supremo Tribunal (onde realizei pesquisa etnográfica de maior fôlego), como pela possibilidade de apresentar um argumento que não exatamente tenta intervir no debate jurídico no sentido de convertê-lo em debate antropológico, mas que aposta justamente na diferença potencial entre três formas de pensamento, três pontos de vista, que atravessam essa controvérsia nos processos judicializados, 
quais sejam a indígena, a antropológica e a jurídica. Sigo, assim, de modo mais ou menos fiel, o que propôs Annelise Riles (2004) para pesquisas que articulam antropologia e direito, especialmente aquelas que envolvem direito de propriedade. Segundo Riles, seria possível observar as diferenças disciplinares pouco articuladas entre os entendimentos antropológicos e jurídicos - e aqui acrescento o indígena -, como uma premissa inicial, mantendo a produtividade dessa diferença.

Se, como dizia Marie-Angèle Hermitte (1999), o direito inventa um outro mundo, talvez seja preciso reconhecê-lo como tal justamente para afirmar seus limites, aquilo que ele não consegue alcançar a partir de sua técnica, quando, neste caso, introduz a noção constitucional de direito "aos usos, costumes e tradições" como prerrogativa (um tipo de reserva) de um outro sistema/forma de pensamento e constituição do mundo, um outro "modo de existência", em relação àquele que o direito se acostumou a resolver. Trata-se de uma outra juridicidade, para usar a expressão de Alexandre Nodari (2016).

Será preciso manter essa diferença, tentando evitar a conversão unilateral e talvez apostando em uma "captura recíproca" (Stengers, 2010, p. 36). Alguma coisa como uma sequência de reversões ${ }^{3}$ entre o que limita e o que é limitado, entre a expansão e a contração de dois ou três modos de pensamento, que, ainda que assimétricos em termos de efeitos, estão, nesse debate, o tempo todo desafiando suas categorias convencionais, e entre modos de pensamento e produção que são várias vezes ultrapassados, ao mesmo tempo que se mostram imprescindíveis.

A técnica jurídica para se aplicar a "[...] situações típicas em que o intérprete começa por reduzir os fatos ou os feitos impondo-lhes uma forma adequada à regra [...]" (Thomas, 2002, p. 1.426), quando opera no caso das terras indígenas, acaba por subverter a própria teleologia constitucional, ou seja, ao invés de reconhecer, proteger e garantir, define e limita o que já se apresenta como um limite por princípio, movimentando uma ordem alienígena às lógicas "nativas". É o que afirma Davi Kopenawa ao identificar o duplo sentido da demarcação (como prisão e como proteção): 
Quem ensinou a demarcar foi o homem branco. A demarcação, divisão de terra, traçar fronteira é costume de branco, não do índio. Brasileiro ensinou a demarcar terra indígena, então a gente passamos a lutar por isso. Nosso Brasil é tão grande, e a nossa terra é pequena. (Pontes, 2015)

O artigo 231 exige e possibilita a antropólogos e a juristas um deslocamento, ou seja, a abertura de um espaço para uma outra experiência de pensamento, ou como me disse certa vez o filósofo Marco Valentim, um "exercício de uma outra imaginação, capaz de produzir vertigem no espírito da abstração monetária". Não se trata de um mundo do dever ser, mas de formas de relação que atualizam modos de viver e produzir a terra e a vida na/com a terra que não admitem determinados cercamentos, como o da propriedade, por exemplo. Para alcançar e traduzir "essa terra", ou a "nossa terra" como dizem os indígenas, é preciso, talvez, um exercício propriamente antropológico.

O exercício de deslocamento das tipologias legais não é novidade no direito; os tribunais têm sido desafiados a repensar sua ontologia que divide e limita o mundo entre pessoas e coisas, sujeitos de direito e objetos do direito, ao se confrontarem com as novas biotecnologias ou com os direitos dos animais (Bevilaqua, 2011). Alain Pottage chega a afirmar que a técnica legal utilizada tradicionalmente por instituições jurídicas para produzir as fronteiras entre pessoas e coisas não é mais autoevidente, assim como a divisão entre natureza e cultura. As categorias de experiência do mundo, diz o autor, como espaço, tempo, ação etc. vem sendo transformadas no curso do desenvolvimento científico e dependem da contingência em que essas divisões são desenhadas (Pottage; Mundy, 2004, p. 8).

O diálogo produtivo entre direito e ciência possibilita que novos arranjos do mundo possam ser incorporados nas doutrinas, pois, como em qualquer prática de conhecimento, existe um movimento de transformação constante no direito, interno ao modo como este se produz e que garante que suas categorias acompanhem as transformações no mundo. As clássicas fontes do direito - a doutrina, a lei e a jurisprudência - não alcançam determinadas relações, nem poderiam. 
Parece ser disso que trata o que se costuma chamar, no direito, de neoconstitucionalismo pós-positivista, que abandona em parte o anseio normativo universal, característico do direito positivo, em nome de princípios norteadores que se aproximam do real. Gunther Teubner, jurista alemão, sugere que diante da diferença entre os discursos, da incomensurabilidade entre eles, é possível pensar mediante o que ele chama de "desentendimentos produtivos" (expressão bastante familiar à teoria antropológica):

Um discurso não pode deixar de reconstruir o significado do outro em seus próprios termos e contexto e, ao mesmo tempo, pode fazer uso do material de significado do outro discurso como uma provocação externa para criar internamente algo novo. (Teubner, 2000, p. 14)

O algo novo aqui seria apenas uma conexão, um "acordo pragmático" (Almeida, 1999) em torno do qual diferentes ontologias podem aliar-se sem criar uma fusão ou subsunção. Aliança que não significa, pois, identidade, mas, sobretudo, abertura.

Talvez este seja um caminho diante de uma das premissas dos julgamentos cujo objeto principal são as demarcações de terra indígena e as disputas em torno delas, a premissa de que se trata de um conflito de interesses no qual o Judiciário deve agir como mediador, encontrando uma posição de "conciliação". Na realidade, ainda que não se possa negar a controvérsia pública em torno das demarcações, em tese não existiria um conflito de direito, dado que, conforme os fundamentos da ideia de direito originário, uma "terra tradicionalmente ocupada" é apenas declarada, o que quer dizer que ela já era indígena antes de tal ato administrativo. Sendo indígena, nada de direito existiria antes dela.

A proteção às terras e às comunidades indígenas é um dever constitucional que coloca o Supremo Tribunal Federal, a quem cabe a precípua guarda da Constituição, como parte dessa garantia. Mas o direito ao reconhecimento da terra não pode estar separado de seus sujeitos (de seus vários sujeitos, é preciso notar). Não se pode, portanto, proteger os direitos constitucionais das comunidades protegendo-se ao mesmo tempo dos índios, evocando os fantasmas dos povos indígenas como se fossem uma ameaça à soberania territorial brasileira - veja-se 
o espanto do Judiciário com a Declaração das Nações Unidas sobre os Direitos dos Povos Indígenas (documento datado de 13 de setembro de 2007), lida como ameaça ao desenvolvimento e à propriedade privada (é preciso proteger Copacabana!), ou ainda lida sob o ângulo da suspeita de que os indígenas não seriam de fato índios e poderiam usurpar um direito que não lhes pertence. Cada um desses riscos emerge, é possível dizer, da replicação da lógica do pensamento estatal de ocupação/conquista do espaço, como se o horizonte de autonomia de uma comunidade/nação indígena tivesse como objetivo a fundação de seu próprio Estado. A tríade segurança jurídica/soberania/ comunhão(interesse) nacional consegue movimentar e paralisar o debate, operando nos limites da imaginação do Estado e de sua relação com seu território, engenhosamente articulados e patrocinados por interesses privados. Vale notar que esses três pilares movimentam justamente a razão estatal que autoriza a política etnogenocída seja no caso das demarcações e reconhecimento de terras, seja na justificativa dos grandes empreendimentos que não apenas afetam povos e comunidades indígenas, como os ambientes através dos quais a vida se produz.

Na busca de articular o debate aqui proposto, descreverei três momentos da conceituação do direito das comunidades indígenas sobre suas terras. A ideia é que a partir deles se possa pensar os deslocamentos políticos-conceituais enfrentados na luta dos povos pelas terras atualmente. O primeiro deles é o voto do ministro Victor Nunes Leal, na ocasião do julgamento da Arguição de Inconstitucionalidade de lei editada pelo estado do Mato Grosso que diminuía a área destinada aos índios naquele estado (em 1961, sob a vigência da Constituição de 1946). No famoso voto, ele afirmava a diferença fundamental entre o que se destina aos índios como terra e o que se funda como desdobramento próprio do direito de propriedade.

Dizia o ministro em seu voto:

Não está em jogo, propriamente, um conceito de posse, nem de domínio, no sentido civilista dos vocábulos; trata-se do hábitat de um povo. Se os índios, na data da Constituição Federal, ocupavam determinado território, porque desse território tiravam seus recursos alimentícios, 
embora sem terem construções ou obras permanentes que testemunhassem posse de acordo com o nosso conceito, essa área, na qual e da qual viviam, era necessária à sua subsistência. Essa área, existente na data da Constituição Federal, é que se mandou respeitar. Se ela foi reduzida por lei posterior, se o Estado a diminuiu de dez mil hectares, amanhã reduziria em outros dez mil, depois mais dez, e poderia acabar confinando os índios a um pequeno trato, até no terreiro da aldeia, porque ali é que a "posse" estaria materializada nas malocas. (RE 44.585, Tribunal Pleno, DJ em 12/10/1961)

A ideia que coloco em suspenso por ora é a ideia de hábitat. Esse destaque ficará mais bem explicitado na articulação com os outros dois momentos que pretendo sublinhar.

O segundo momento é constituído por algumas imagens que vou tentar descrever parcialmente. São imagens que aparecem nos anais do processo constituinte de 1987, o qual consolidou o artigo 231, retiradas das descrições do livro "Os Povos Indígenas e a Constituinte" editado pelo Conselho Indigenista Missionário:

Em 26 de agosto de 1987, em meio a escândalos produzidos pela campanha difamatória contra o Cimi veiculada pelo "Estadão", e às vésperas da instalação da Comissão Parlamentar Mista de Inquérito destinada a apurar aquelas falsas acusações de conspiração internacional contra a soberania brasileira, o relator da Comissão de Sistematização, deputado Bernardo Cabral, apresenta o primeiro substitutivo ao Projeto de Constituição [que havia sido aprovado na Comissão Especial de Minorias]. Era o seguinte o seu teor [do substitutivo]:

São terras reservadas aos indígenas:

[...] $\mathrm{x}$ - as terras de uso imemorial onde se acham permanentemente localizados os índios;

Art. 303 As terras de posse imemorial dos índios são destinadas à sua posse permanente. (Lacerda, 2008, p. 126)

Esse projeto substitutivo foi lido pelas entidades indígenas e indigenistas como um retrocesso em relação ao texto original. Seu relator Bernardo Cabral introduzia um conceito restritivo que passava a ter como critério para identificação e demarcação o "caráter imemorial" 
da posse em vez da ocupação tradicional da terra. O substitutivo do relator foi apoiado pelo então presidente da Funai, Romero Jucá, que acrescentava ao texto a expressão "onde se acham permanentemente localizados". Foi também em razão desse substitutivo que Ailton Krenak discursou na plenária da assembleia, pintando o rosto com jenipapo, numa das imagens de maior impacto da participação indígena no processo constituinte.

A participação de Ailton Krenak, assim como a de várias outras lideranças indígenas, foi bastante intensa durante todo debate constituinte. Na Subcomissão de Minorias, Krenak, seu discurso sintetizou as controvérsias em torno dos direitos indígenas naquele momento e colocava a terra no centro do debate:

Não estamos pedindo absolutamente nada a ninguém, estamos sim exigindo respeito, o respeito por sermos os primeiros habitantes desta terra que hoje chamam Brasil. Somos habitantes originários desse lugar. O respeito e o acatamento do nosso povo é o mínimo que nos devem. Há muita gente nesse lugar hoje, e não podemos jogar todos vocês de volta no mar, deveríamos ter feito isso em 1500 , quando chegou uma só caravela, mas não fizemos por uma série de razões, e resolvemos conviver e construirmos ao longo desses quatro séculos uma experiência dolorosa de relação humana, uma relação trágica que consumiu 90\% da nossa população. [...] não adianta os senhores formularem uma proposta culturalista, não adianta formular uma proposta que venha contemplar o direito do índio falar sua língua, dançar a sua festa e usar o seu cocar, porque antes de tudo é preciso ter uma terra para pisar em cima. (Lacerda, 2008, p. 190)

O terceiro momento é o voto, desta vez já na vigência da Constituição de 1988, do ministro Nelson Jobim, em uma Questão de Ordem por ele mesmo levantada, relativa à Ação Civil Originária 312, da qual era relator e que consistia em um pedido da Funai para anulação de 396 títulos de propriedades incidentes na Reserva Indígena Caramuru-Paraguassu, no sudeste da Bahia, onde vive o povo Pataxó Hã-Hã-Hãe. No voto, o ministro evoca a imagem de quatro círculos concêntricos quanto aos critérios e à elegibilidade de uma terra qualificada como indígena. O primeiro círculo seria o da habitação permanente; o segundo, o 
da utilização para atividades produtivas; o terceiro, da preservação dos recursos naturais necessários; e, por fim, o círculo exterior da reprodução física e cultural. Esses círculos, na lógica do argumento, seriam codependentes; deveriam ser cumpridos em sequência para que ao final se pudesse avaliar e decidir a aplicação da qualificante terra indígena. Em outras palavras, os círculos se tornariam critérios mais ou menos objetivos e hierarquizados, através dos quais seria possível aferir e qualificar a terra, sua dimensão e extensão.

A sequência do argumento afirma então que a expressão constitucional "terra tradicionalmente ocupada" diz respeito ao modo de ocupação enquanto forma de posse e como medida para excluir qualquer ideia de imemorialidade da terra. A teoria dos círculos concêntricos desdobrou-se na fala do ministro, já aposentado, durante a CPI da Funai, no tocante ao julgamento da Terra Indígena Raposa Serra do Sol, como a concretização de sua teoria (e, de fato, os círculos concêntricos vão aparecer em quase todos os votos dos ministros, na ocasião de tal julgamento).

Diz o ministro em seu depoimento à CPI:

[...] ficou fixado - observem bem - que a posse daquelas terras habitadas em caráter permanente, eram aquelas que estavam sendo habitadas na vigência da Constituição. Com isto, o Supremo acolhe a decisão da Constituinte de 1988 que rompeu com o conceito de posse imemorial. Ou seja, não foi constitucionalizado o conceito de posse imemorial, que era a posse que tinham; e, porque tinham a posse, deveriam continuar a tê-la, embora no presente não a tivessem. Este assunto encerrou-se com a decisão do Supremo, o que já se repetiu em alguns outros casos, fixando o marco temporal em outubro de 1988. (Brasil, 2017, p. 15)

O que quero sublinhar dessa intepretação judicial são as ideias aparentemente contraditórias entre imemorialidade e tradicionalidade. Tendo estabelecido esses movimentos, o passo seguinte não é avaliar cada um deles, porém pensar através deles, tentando estabelecer o que significa ou pode significar o reconhecimento aos índios de sua terra a partir de seus usos, costumes e tradições, conjurando os efeitos e desdobramentos das decisões do STF e a conexão entre a "vitória" e a 
"derrota" da decisão de Raposa Serra do Sol na proteção e na garantia da terra. A análise se concentra, sobretudo, nas passagens e nas frestas por onde o reconhecimento de uma terra indígena é transportado, ou seja, no trajeto que vai da teleologia constitucional ao processo administrativo e do processo administrativo aos processos jurídico.

\section{Terra Sem Lei}

Não pretendo traçar toda a genealogia do direito indígena na história das Constituições brasileiras, independentemente do marco inicial de reconhecimento adotado, seja o Alvará Régio de 1680, seja a Constituição de 1934. Contudo, vale a pena recuperar, ainda que parcialmente, alguns dos debates ou ideias que são, ou ao menos aparecem recorrentemente nessa história como tal, fundamento do direito às terras reservadas às comunidades indígenas. A ideia mesma de um direito originário perfaz o primeiro destes debates: "Se reconhecem aos índios os seus direitos originários", essa é a expressão da Constituição Federal. Diferentemente de um direito criado por meio da lei, um direito reconhecido carrega determinadas implicações para a própria interpretação jurídica. No caso indígena, reconhecendo esse direito, assevera-se que ele já existia antes da lei, ou seja, é a ela préexistente, o que restringe o escopo da atuação estatal às ações protetivas e declaratórias. Sendo anterior à lei, não é um direito disciplinado pelos requisitos de posse ou propriedade.

Reconheceu-se assim que entre uma comunidade indígena e a sua terra existe uma relação que não se enquadra nas tipologias do ordenamento do Estado, ainda que possa ser análoga a várias delas. Não é posse, ainda que também possa sê-lo; não é propriedade, ainda que possa assim parecer. Nenhum desses tipos ou instrumentos funciona ou pode ser acionado plenamente, na medida em que se trata de sociedades que não vivem (ou pelo menos não viviam) sob a égide da ficção moderna do contrato e do Estado-Nação, no qual a propriedade funciona como instrumento central protegido pelo direito. A posse e a propriedade envolvem relações de domínio e controle entre pessoas e coisas ou uma relação entre pessoas mediadas por coisas e baseada na exclusão - aquilo que é meu é justamente aquilo que não é de outro 
-, enquanto a relação indígena evocada pela ideia da "nossa terra" estabelecer-se-ia por meio de relações diferenciadas entre sujeitos e agentes que constituem não qualquer terra, mas uma terra específica criando uma zona de indiscernibilidade entre agenciamentos. Alexandre Nodari (2016, p. 1), no recente texto “Recipropriedade: ocupação e cuidado com a T/terra", sugere que a relação indígena com a terra poderia ser traduzida aproximadamente através de um conceito que o autor chama de "recipropriedade", que ativa a reivindicação "[...] de uma outra relação com a terra, baseada no contato e na ocupação". O conceito conecta pelo menos duas outras figuras, a "posse contra propriedade" ${ }^{4}$ de Oswald de Andrade, e a possessão recíproca de Gabriel Tarde . Ao propor o conceito, Nodari afirma que se trata "de invocar, contra o Estado e a propriedade, uma concepção ou imagem da terra antes do Estado e da propriedade, tanto temporalmente quanto ontologicamente". Citando o antropólogo Eduardo Viveiros de Castro, o autor aponta que "talvez seja comum, entre diversos povos indígenas, uma figura 'jurídica' complementar à da 'posse contra a propriedade', que se revela na ideia de a "propriedade sem a posse"'. A sugestão de Nodari tenta escapar da intepretação do direito que equaciona posse civil e posse indígena, dado que não são disciplinadas pelas mesmas regras, nem tampouco se referem à mesma coisa ou relação. Portanto, ao tentar abstrair as relações concretas desses povos com a "sua terra" a atenção recairia sobre as outras formas de territorialidade que não se convertem em ocupação como permanência e domínio efetivo, mas em cuidado e constituição recíproca entre sujeitos.

Diferentemente da posse civil, a posse indígena - termo que uso apenas transitoriamente - não consolida uma situação de fato - a ocupação e o domínio - em uma situação de direito, já que, ao contrário, a situação teria sempre sido de direito. Não se pode adquirir por meio da lei aquilo que já era tido como seu. A afirmação pode ser lida apenas como uma tecnicalidade, mas são os efeitos dela que merecem destaque. O que a lei faz é "simplesmente" reconhecer a "nossa terra", as terras das comunidades, seus vínculos tradicionais que se atualizam em determinados lugares. A propriedade das terras tradicionalmente ocupadas não pertence aos índios, mas à União, ou 
seja, ao Estado, responsável por proteger o usufruto exclusivo das comunidades, sua imprescritibilidade e inalienabilidade, seu direito à posse permanente - posse aqui como aquilo que a lei deve garantir e não como critério de reconhecimento. "Se destinam a sua posse permanente", são os termos precisos da Constituição.

Era essa diferença que estabelecia o instituto do indigenato, hoje tão desprestigiado pelo Poder Judiciário em nome daquilo que se chamou (no voto do ministro Meneses Direito, durante o julgamento da Petição de Raposa Serra do Sol) de "teoria do fato indígena". O instituto do indigenato não estabelecia a imemorialidade como condição do direito, mas a postulava como origem, afirmando a posse diferenciada, que é ao mesmo tempo originária/congênita - anterior - e original.

Não é posse, é hábitat, argumentava Nunes Leal. Aos índios não se reservou, como aduz o ministro, um direito de fato a ser exercido sobre um objeto (a terra) por meio da posse. O que está em questão é o hábitat de um povo, de vários povos, é preciso lembrar. Partindo da constatação do ministro, a aposta no hábitat enquanto categoria pode permitir uma recomposição da espacialidade indígena que escapa das noções jurídicas de posse e domínio efetivo, enquanto domesticação e submissão do ambiente. A ideia de hábitat evoca uma noção de pertencimento, de ambiente social e cultural, que possibilita a vida. O hábitat de um povo relaciona uma dupla integração/constituição entre o sujeito que habita e o objeto/sujeito a ser habitado. Segundo Ingold (2011), a ideia de hábitat envolve não apenas a organização do espaço, mas também do tempo e dos significados. Trata-se, como sugere o autor, de uma contraposição entre a "perspectiva da construção (edificação)" enclausurada no "familiar modelo segundo o qual o trabalho produtivo serve meramente para transcrever formas ideais preexistentes sobre um substrato natural inicialmente amorfo" e a "perspectiva da habitação". Isso não significa negar que os seres humanos construam coisas, mas sobretudo, "solicitar uma explicação alternativa para construção, como processo de trabalhar com materiais, e não apenas produzi-los, e de trazer forma à existência, não meramente traduzir do virtual para o real" (Ingold, 2011, p. 35).

Parte desse dossiê e parte das pesquisas vinculadas ao projeto $\mathrm{T} /$ terras colocam no centro do debate os diferentes modos de constituição/ 
produção de lugares entre comunidades indígenas de diferentes etnias. Resguardadas as diferenças entre cada comunidade ou cada povo, pode-se dizer, em comum, que a "nossa terra", a terra indígena, é composta de "pessoas e lugares constituindo-se reciprocamente, os lugares que estabilizam a perspectiva dos seres seus habitantes, de modo que estar em um lugar implica estabelecer uma relação com a perspectiva dos seres para os quais aquele lugar é uma aldeia ou um território" (Nunes, no prelo). São modos de viver que combinam espaços e tempos distintos (Otero, no prelo), em que os fundamentos das relações de propriedade se tornam um esquadro pouco operacional para pensar naquela outra relação.

Em contraste com o modelo estatal/moderno de conquista do espaço, em que este aparece como expansividade e uniformidade, ideias que implicam uma espacialidade quantificável e mensurável (Malpa, 1999, p. 3), a ideia do lugar, tal como aparece em Nunes e Otero, "tem um conteúdo e caráter que pertence a ele - e como tal é essencialmente qualitativo" (Malpa, 1999, p. 4). Isto é, existe uma heterogeneidade fundamental; os lugares comportam diferenças dentro deles, além de serem diferenciados de outros lugares (Id. Ibid.). A aposta de produção de lugares sempre particulares e, portanto, a serem descritos e não prescritos, funcionaria como um antídoto, um contradispositivo para uma definição externa às próprias relações, que converte lugar em espaço, "unidade transcendente, que é a unidade do Estado" (Malpa, 1999, p. 4).

Esses modos nativos de ocupação, que transformam os lugares em diversos espaços, quando passam da esfera da vida à esfera da lei vão sofrer outras transformações, tendo em vista a diferença já destacada entre a "nossa terra" e uma Terra Indígena. Não podendo reconhecer a terra indígena em toda sua extensão e intensidade, o recorte nessa terra se faz, pelo menos desde 1988, a partir da ideia da tradicionalidade: se reconhece e se garante a 'terra tradicionalmente ocupada', conceito jurídico cujo conteúdo depende das situações concretas em que a tradicionalidade pode ser vivida, apreendida e descrita. A ocupação tradicional, portanto, não depende dos critérios jurídicos, mas se consolida a partir da prerrogativa dos "usos, costumes e tradições". 
É justamente aí que reside a possibilidade de uma convergência divergente entre as categorias legais e a apreensão nativa da terra, na afirmação de que existe um ponto de vista específico que torna os vínculos com a terra vínculos tradicionais. Ou seja, se a terra indígena é presumida, a tradicionalidade é uma relação perspectiva dos sujeitos coletivos que estão na terra. Ressalta-se aqui a diferença apontada pela ministra Rosa Weber entre estar na terra e estar sobre a terra (voltaremos a isso na seção seguinte). Trata-se então de uma quebra do monopólio do ponto de vista jurídico e estatal em nome de uma jurisdição indígena.

\section{Do Administrativo ao Jurídico}

Pode-se imaginar que na passagem daquilo que se anuncia pela doutrina jurídica clássica como sendo os pressupostos constitucionais do artigo 231, que explorei até agora, para o procedimento administrativo concreto de regularização das terras, algumas transformações sejam operadas, ou, mais precisamente, alguns deslocamentos importantes desses fundamentos retornam ao lugar comum da regularização fundiária. A circulação do conceito na esfera pública e nas disputas de modelos fundiários a serem gerenciadas pelos órgãos de regularização é capaz de desgastar os fundamentos iniciais do direito originário em nome de modelos "possíveis" ou "conciliáveis" de administração das demandas indígenas pela demarcação. Essas passagens do direito à política e da política à técnica de identificação tem o poder de desestabilizar alguns dos fundamentos que pareciam consensuais, especialmente a diferença postulada entre posse e hábitat; ainda que, sem essa diferença, todas as outras percam parte de seus efeitos.

A forma como o Estado brasileiro concretiza seu dever constitucional de demarcação se faz por meio de um processo administrativo regulamentado pelo Decreto Presidencial n. 1.775, de 1996, e pela portaria 14 do Ministério da Justiça, do mesmo ano, entre outros dispositivos que dispõem sobre a forma pela qual se pode aferir e qualificar uma terra como "indígena". Composto pelas etapas de identificação, declaração, homologação e registro, esse processo/ 
procedimento transporta, através de uma sequência de documentos, o conjunto de ideias mais abstratas que fundamentam o direito, até o objeto concreto que é uma terra identificada, homologada e, portanto, protegida.

Aqui me concentrarei nos efeitos da Portaria n. 14 e no julgamento da demarcação contínua da TI Raposa Serra do Sol, conectando esses dois movimentos - a edição da portaria e o julgamento da TI - ao risco de desestruturação da "conquista" representada pelo artigo 231.

A etapa fundamental de todo processo administrativo de demarcação, aquela capaz de identificar a terra tradicionalmente ocupada, ou seja, os vínculos que se estabelecem em lugares específicos que perfazem uma Terra Indígena, é assegurada por meio de relatório técnico antropológico. Como documento sobre o qual irão se basear todos os demais procedimentos do processo, não é surpreendente que seja essa etapa a mais controversa de toda regularização e que seja a ela que se enderecem todas as tentativas de instrução processual, ou seja, as tentativas de controle do processo. A expertise antropológica é necessária à identificação do hábitat, realizada a partir do recorte espaçotemporal próprio das comunidades cuja tradicionalidade da ocupação é reconhecida. O trabalho dos relatórios de identificação envolve "uma reconstituição dos vínculos (relações e memórias) existentes entre as pessoas e a(s) terra(s)" (Miras, 2015), e transporta para os relatórios a legitimidade de sua metodologia científica. É justamente tentando disciplinar essa identificação que surgiu a portaria em questão.

Tanto a Portaria n. 14 quanto o Decreto n. 1.775, editados pelos então Ministro da Justiça Nelson Jobim e Presidente Fernando Henrique Cardoso, entraram em vigor em 1996. O objetivo do decreto, segundo o ministro, seria o de sanar a falta do contraditório nos processos administrativos de demarcação que corriam o risco de serem declarados inconstitucionais pelo STF. Já a Portaria seria responsável por disciplinar o que deveria ser preenchido nos relatórios antropológicos baseado numa interpretação específica do que seja uma "terra tradicionalmente ocupada". Na análise de Henyo Barreto Filho (2005, p. 11), esta portaria apresentava

Um entendimento restritivo da definição constitucional de "terras tradicionalmente ocupadas pelos índios", consolidado na norma jurídica como conceito 
consubstanciado, "em conjunto e sem exclusão", pelas "quatro situações previstas no $\S 1^{\circ}$ do art. 231 da Constituição" (termos da Portaria n. 14; ênfases minhas), quais sejam: (1) as áreas habitadas pelos índios em caráter permanente, (2) as áreas utilizadas para suas atividades produtivas, (3) as áreas imprescindíveis à preservação dos recursos ambientais necessários a seu bem-estar, e (4) as áreas necessárias à sua reprodução física e cultural, segundo seus usos, costumes e tradições.

A teoria dos círculos concêntricos começava a ser desenhada a partir da Portaria, mesmo que a separação e a hierarquia entre as "situações" não estivessem claramente colocadas. A tradicionalidade como modo de ocupação, não o dos índios, mas o da lei, aqui começa a ser produzida a partir de um desalinhamento entre de um lado a proteção e garantia e de outros requisitos de necessidade. Carlos Fausto chega a afirmar que a portaria 14 restitui "o velho conceito de posse no sentido civilista tantas vezes mobilizado no passado pelos interesses anti-indígenas, segundo o qual a posse de um território manifestar-se-ia pela presença de edificações e áreas de cultivo permanente" (Fausto,1998, p. 6). No entanto, mesmo se o horizonte do documento pudesse ser lido como uma conversão ou reversão dos sentidos propriamente constitucionais de garantia da integridade espaço cultural dos povos indígenas, a restrição não se sustenta; ou pelo menos não se sustentou quando movimentada e operacionalizada pela metodologia antropológica que conseguiu, no interior do processo, garantir certa autonomia técnico- científica. O próprio STF já se manifestou nesse sentido: “O que importa para o deslinde da questão é que toda a metodologia propriamente antropológica foi observada pelos profissionais que detinham competência para fazê-lo" (Brasil, Petição n. 3.388-4-RR)

$\mathrm{O}$ "propriamente antropológico" seria, assim, aquilo capaz de traduzir o que pode significar o "propriamente indígena". Se, como afirma Barreto, uma interpretação restritiva do artigo 231 pode se consolidar como dispositivo normativo (Portaria n. 14) a partir das manobras políticas em torno das supostas ambivalências do próprio texto constitucional, os casos concretos em que a portaria atua como orientação asseguram-lhe uma interpretação que logra aferir a "terra tradicional" em sua integridade sociocultural, justamente na medida 
em que só pode se basear na própria aferição dos coletivos indígenas. Trata-se da captura da prescrição restritiva e limitante subvertida pelas descrições antropológicas comprometidas com o dever constitucional de fazer emergir nesses processos um ponto de vista específico. Mas não se trata certamente de uma antropologia que toma partido, e, portanto, se torna parte de uma disputa de terras, mas aquela de um conhecimento capaz de evidenciar as partes que perfazem essa disputa.

Já nos processos judicializados, especialmente no caso de Raposa Serra do Sol, a interpretação do artigo 231 se movimenta de um modo pouco diferente. As contestações judiciais realizadas no primeiro momento contra os atos da Funai levam os processos às primeiras instâncias do Poder Judiciário. As controvérsias levantadas pelos "proprietários" nesses processos se aglomeram nas várias ações jurídicas até que cheguem ao STF criando um tipo de pressão processual em torno das demarcações, capazes de causar, justamente pelo acúmulo (a quantidade de processos judicializados), uma ideia de que os instrumentos de demarcação teriam chegado ao seu limite, estariam desgastados e precisariam ser revistos ou atualizados. De modo geral, os argumentos de contestação dos procedimentos a) questionam a parcialidade dos relatórios técnicos antropológicos, tendo em vista que os não índios interessados nas terras demarcáveis poucas vezes conseguem contradizer os relatórios a partir de sua própria metodologia; b) apresentam a autoidentificação como critério movediço aberto a fraude; c) contestam o tamanho das terras em relação ao número de indígenas de cada comunidade, e d) reivindicam a suposta falta de produtividade das TIs, o que geraria um "custo alto ao país". Essas questões circulam pelos tribunais relacionadas ao debate sobre segurança jurídica e soberania nacional. O caso de Raposa Serra do Sol se tornou exemplar nesse sentido, tanto pelo tamanho da terra (o que é levantado sem qualquer referência ao tamanho dos latifúndios no Brasil, por exemplo), como pelo "prejuízo" às cidades e à economia da localidade. Como não são todos os processos de demarcação judicializados que irão chegar ao STF e serem julgados pelo plenário da Corte, esse caso se tornou um modelo por meio do qual o tribunal responderia parte das contestações que circulam em 
torno das demarcações e não apenas daquela, ainda que a decisão de uma Petição como o processo de Raposa não tenha formalmente um efeito vinculante a outras decisões.

A resposta do STF nesse processo foi traçada a partir de dois caminhos distintos, ainda que formulados dentro dos mesmos argumentos. A maioria dos ministros não refutou a diferença entre posse no sentido civilista e hábitat, consolidada pelo menos desde o voto do ministro Nunes Leal e replicada em todos os julgamentos da corte envolvendo a questão indígena. A dívida histórica em relação aos povos indígenas bem como a necessidade de demarcação como garantia da sobrevivência sociocultural desses povos formadores da "identidade nacional" foram colocadas como horizonte a ser alcançado pela decisão. A falsa oposição entre proteção da cultura e da terra e desenvolvimento nacional foi desmontada; o contraditório administrativo foi garantido como proporcional ao tipo de procedimento em questão. E, mais importante, ratificou-se o direito à terra destacado como o equivalente ao direito à vida dos coletivos indígenas. Foi o que asseverou o ministro Menezes Direito, repetindo a afirmação de várias, se não de todas, as comunidades indígenas: "Não há índio sem terra. Tudo o que ele é o é na terra e com a terra. [...] A posse da terra é essencial à sua sobrevivência". Pode-se concluir que o direito à terra nada mais é que o próprio direito fundamental desses povos. Parecia assim que a decisão não faria senão afirmar os fundamentos que orientam a intepretação do oitavo capítulo da CF.

Qual então é o risco da decisão sobre a Terra indígena Raposa Serra do Sol, se as premissas que parecem orientadoras de uma interpretação consistente compuseram o debate do julgamento e, principalmente, o voto condutor da decisão? Diferentemente das equivalências que orientavam a edição da Portaria n. 14, em que o hábitat se convertia em posse, as conversões nos julgamentos do STF são menos evidentes na lógica dos argumentos, ainda que mais graves em termos de efeitos. Antes de expor dois momentos dos votos, destaco uma primeira questão que apareceu no debate como detalhe, quase uma anedota, mas que me parece marcar a preocupação fundamental desses processos. Ao abrir seu voto, um dos ministros lembra ter lido nos autos processuais um 
diálogo entre um representante do Ministério Público e um antropólogo que estavam na TI. Durante essa conversa, o representante do MPF teria perguntado ao antropólogo se aqueles indígenas, que pareciam gostar muito de futebol, torciam pela seleção brasileira. Diante da resposta negativa do antropólogo, o ministro acende um alerta. Um juiz acostumado a ler o mundo a partir das teorias do Estado e do Direito imediatamente é capaz de desdobrar a anedota em uma preocupação que envolve o debate sobre soberania e segurança nacional: haveria espaços grandes demais e estratégicos demais para serem colocados em risco. Encobertas pela segurança nacional e jurídica, as premissas fundamentais - a saber, terra é vida e tradicionalidade é modo de ocupar, é vinculo com a terra - são neutralizadas, perdem a referência da diferença que funda a própria ideia de hábitat e de direito originário. A preocupação e o risco foram (e são) capazes de impor aos povos indígenas, em um único processo, um novo contrato, que, a despeito da vitória e dos avanços assegurados pela $\mathrm{CF} / 88$, lhes impõe uma derrota de direito, ainda que não tenha havido uma derrota de fato no próprio processo constituinte.

A conversão da diferença pode ser observada em pelo menos dois momentos distintos daquele julgamento. O primeiro deles é a retomada da tese dos círculos concêntricos, que já aparecia de modo mais ou menos explícito na Portaria n. 14 e que se sedimentou no voto no ministro Jobim, já, então, como juiz do STF, sendo reativado como referência para a decisão sobre Raposa Serra do Sol.

A intepretação do artigo 231 baseada na habitação, no sentido de moradia - e não no hábitat, na utilização, na permanência e na produção observáveis a partir de elementos de ocupação e exploração que percebem o espaço a partir da função e do uso - fragmentou a terra tradicionalmente ocupada em áreas que se tornam "[...] segmentadas em quatro elementos: situações - às quais se dá uma conotação espacial" (Fausto, 1998, p. 6). Cada um dos círculos concêntricos qualifica, assim, os vínculos e a necessidade da terra a partir de uma estrutura de valor - aquilo que é mais ou menos objetivo, mais ou menos necessário, em cada uma dessas porções. 
De acordo com Coelho de Souza et al. (2017),

A noção de que tais critérios [...] possam ser ordenadas em círculos concêntricos, e, ainda por cima, de que o circulo interior, da habitação permanente, reduza-se às áreas de edificação de casas/aldeias - de modo que os vínculos com a terra fossem mais sólidos aqui do que na periferia (antigas aldeias e cemitérios, por exemplo), é absolutamente inaplicável no contexto dos modos concretos de ocupação indígena, e acarretaria a sua total desestruturação.

A habitação como núcleo do direito transforma as demais porções a serem demarcadas em "áreas anexas". A hierarquia de vínculos capaz de dividir solo e subsolo, riqueza e cultura, produção e reprodução, provoca o deslocamento da terra como coexistência (Soares-Pinto, 2017, p. 3) ou participação (Nunes, no prelo), em nome de uma terra de produção e exploração, medida a partir dos critérios de animus e corpus: a detenção material do objeto (a terra) e a vontade/necessidade de tê-lo. Requisitos da posse civil, ainda que mesmo nas teorias civilistas de posse, o suposto possuidor não está obrigado a dispor da coisa, bastando a possibilidade da disposição.

O segundo momento que pretendo destacar, e que não se separa do primeiro em termos de efeitos, é o que se chamou no tribunal de marco temporal de ocupação, segundo o qual a "habitação permanente" se fundaria na ideia de ocupação efetiva a ser constatada por meio da "presença constante e persistente" (termos do voto do ministro Menezes Direito), capaz de criar uma "continuidade suficiente para alcançar o marco objetivo de 5 de outubro de 1988" (trecho do voto do ministro Carlos Ayres Brito), constitutiva de uma perspectiva espaço-temporal que não a dos próprios coletivos que, a seu modo, ocupam a terra.

Parece-me existir aqui um equacionamento ou uma equivalência deslocada e confusa entre imemoriabilidade, aldeamentos extintos, terra original e tradicional que seria capaz de impactar de forma desmedida o ordenamento jurídico. Como se não fossem os índios, ao longo da história do Brasil, as vítimas dos esbulhos, expropriações, invasões e massacres - o lado mais vulnerável na disputa de terras. O que na Constituição substitui o imemorial não é o atual ou permanente, mas o 
tradicional, como modo de relação e de ocupação, e não de posse. Entre a negação da terra imemorial e a ocupação contínua e permanente, existe a atualização dos pertencimentos tradicionais com determinadas terras que tornam uma terra especifica aquela reivindicada como "tradicionalmente ocupada". O paradoxo do marco temporal é que ao mesmo tempo que afirma a tradicionalidade como modo de ocupar, retirando a temporalidade da ocupação para excluir o imemorial ou a terra "original" (ou Copacabana), aplica uma temporalidade descontínua no reconhecimento. Ao estabelecer uma continuidade suficiente acaba por provocar uma descontinuidade generalizada, que por um lado ignora que o reconhecimento das terras destinadas aos índios já constava nas Constituições brasileiras anteriores, pelo menos desde 1934, como argumenta José Afonso da Silva em parecer emitido ao Ministério Público Federal sobre o tema, e de outro, ignora a história continuada e violenta de expropriação das comunidades indígenas, transformando o direito originário em conflito possessório. Se a demarcação em tese funcionaria justamente para proteger as terras dessas comunidades, reconhecendo em certa medida a necessidade de reparação contra a violência da colonização e a proteção do futuro desses povos, marcar o direito ao reconhecimento a partir da Constituinte, apagando as marcas, na legislação, da violência que a antecedeu, parece se constituir como uma proteção insuficiente e desproporcional. À presença persistente sobre a terra falta acrescentar, parece-me, a presença insistente na terra. O marco temporal colocado do modo anunciado naquele julgamento se torna anterior à própria tradicionalidade, na medida em que uma terra pode ser tradicionalmente ocupada e não demarcada em favor daqueles grupos que de modo contingente não alcançarem a data de 5 de outubro de 1988.

Ao anunciar tal marco em seu voto, o ministro Ayres Brito alegou ter tentado evitar, a um só tempo, "a fraude da subitânea proliferação de aldeias, inclusive mediante o recrutamento de índios de outras regiões do Brasil, quando não de outros países vizinhos, sob o único propósito de artificializar a expansão dos lindes da demarcação" e a "violência da expulsão de índios para descaracterizar a tradicionalidade da posse das suas terras, à data da vigente Constituição". Se a primeira alternativa 
é bastante controversa, a segunda se esvazia de efeitos quando se desvincula da desproporcionalidade de força entre índios e não índios.

Os efeitos tanto do marco temporal como dos círculos concêntricos distanciam-se de seu objetivo de proteção, assegurando apenas uma "escolha que prestigia a segurança jurídica" dos não índios "invasores" de terras indígenas, desintegrando o que é o núcleo do artigo 231, que pressupõe que a identificação da terra tradicionalmente ocupada se dê "em conformidade com a cultura e o modus vivendi que se deseja preservar" (trecho do voto do ministro Menezes Direito). Para inverter a lógica que reduz as vitórias a derrotas, talvez seja preciso extrair dos enunciados suas consequências e avaliar seus efeitos, o que pode significar um recuo da posição de quem decide.

Ainda que os efeitos dessa decisão tenham aparecido em outros dois processos, nos quais as comunidades tiveram a demarcação negada pelo marco temporal, a quantidade de ações judiciais envolvendo essa mesma questão de fundo vai levar, novamente, o debate ao plenário do STF.

\section{Um Lugar Fora do Direito}

Para terminar, pretendo voltar ao começo recuperando uma intepretação acionada pelo jurista Carlos Frederico Marés (2013) do artigo 231. Conforme o autor, o texto da CF expressa justamente o direito das comunidades indígenas de formar uma ordem legal distinta que, ao ser reconhecida, deixa de ser definida em termos de uma ordem externa e posterior a ela. Seguindo tal argumento, não é a técnica legal aquela capaz de dar conteúdo aos termos constitucionais, mas

[...] a Constituição de 1988 reconhece como legítima uma ordem que desconhece, já que fundada nos chamados usos, costumes e tradições. Esta ordem pode ser descrita por um cientista, sociólogo ou antropólogo, ou relatada por um membro da comunidade, mas está fora do alcance da lei e de seus limites; é uma ordem social própria e diferente da ordem jurídica estatal organizada pela Constituição. (Marés, 2013) 
No argumento de Marés, a CF teria criado um tipo de empty place (Riles, 2002), que, ainda que criado pelo Estado, evidenciaria um conjunto de lugares reais protegidos do seu alcance e também um conjunto de possibilidades anti-hegemônicas para viver à sombra da hegemonia. A implicação disso sobre a noção de "terra tradicionalmente ocupada" é que esta, ao remeter a uma ordem que está fora do alcance da lei e de seus limites, torna-a um conceito sem determinação de princípio;

[...] como conceito jurídico, ele precisa ser 'preenchido', dotado de um conteúdo específico, por uma interpretação antropológica que garanta que, em cada caso, sejam respeitados e garantidos aos índios os 'usos, costumes e tradições', os quais são sempre específicos a um coletivo particular. (Coelho de Souza et al., 2017)

Essa necessidade é o que precisamente justifica o recurso à expertise antropológica no processo administrativo.

Os modos de ocupar tradicionalmente, de estar na ou sobre a terra, de resistir e insistir na terra, estão no ponto cego do direito, na medida em que parecem de fato transgredir o ordenamento, não para se separar dele, mas para, mantendo seu modo próprio, integrar-se a ele. Uma integração que supõe a diferença em toda a sua extensão e intensidade.

Um dos aspectos cruciais da governabilidade dos "Estados Culturais" do qual fala Riles (2002) - qualificante que se aplica a Estados Nacionais formados pela diversidade étnico-cultural - é o de impor um limite à esfera da lei, restringindo sua gerência sobre a esfera da cultura. Se a condição para se aplicar o direito é sempre a predeterminação externa ao mundo da vida, nos processos de identificação das "terras tradicionalmente ocupadas" está claro que os instrumentos jurídicos não fazem senão impor uma intepretação deslocada, cujos efeitos se separam dos objetivos, de modo a alinhar as decisões não com o espírito da garantia e do reconhecimento à diversidade, mas como limitante do direito à vida. Isso não significa que se deva descartar o direito, mas, ao contrário, implica tornar as decisões dos tribunais abertas à experiência antropológica e, sobretudo, à experiência indígena. Reativar o espírito de proteção da Constituição Federal de 1988, estando atento à 
advertência quase profética de Nunes Leal: "se ela [a terra indígena] foi reduzida por meio da lei; se o Estado a diminuiu em dez mil hectares, amanhã a reduziria em outros dez, depois, mais dez, e poderia acabar confinando os índios a um pequeno trato, até ao território da aldeia, porque ali é que a 'posse' estaria materializada nas malocas. Não foi isso que a Constituição quis".

\section{Notas}

1 Com a retirada de uma das ações da pauta de julgamento o debate sobre o marco temporal não aconteceu, de fato, entre os ministros. As duas decisões tomadas diziam respeito a terras demarcadas antes de 1988, portanto, não se aplicaria qualquer marco de tempo de ocupação nesses casos.

2 A CPI Incra/Funai foi instalada em 2015 na Câmara dos Deputados com o objetivo, segundo consta em seus documentos, de apurar irregularidades nos processos de demarcação de terras indígenas e quilombolas. Foi presidida pelo deputado Nilton Leitão (PSDB-MT), também coordenador da Frente Parlamentar Mista da Agropecuária no Congresso (braço do agronegócio na famigerada "Bancada BBB" - do Boi, da Bíblia e da Bala, grupo de parlamentares que tenta exterminar as conquistas cidadãs e populares advindas com a Constituição de 1988). A CPI foi formada por apoiadores do Projeto de Emenda Constitucional 215, que tenta transferir da Funai para o Congresso Nacional a competência para demarcar terras indígenas.

3 Como num aparelho de auto reverse, nas palavras do voto do ministro Ayres Brito, "pois também eles, os índios, têm o direito de nos catequizar um pouco".

4 Ainda segundo Nodari (2007, p. 110), em outro texto, “[...] definir juridicamente a posse implica distinguir o momento em que o direito toca a vida: por isso, a interminável discussão jurídica em torno do seu estatuto - se é fato ou se é direito -, ou melhor, a respeito de como uma apropriação física produz consequências jurídicas e gera direitos (e, por contrapartida, quando é um mero fato), discussão que rendeu diversas soluçôes legislativas e proliferação de parainstitutos legais (detenção - nuda detentio, posse ficta - ficta possessio, posse indireta, etc.), discussão em que, não por acaso, se envolveram dois dos maiores romanistas (isto é, especialistas justamente da "origem" do Direito ocidental) do século XIX, Savigny e Ihering (mas também Guns, primeiro editor de Hegel), essa discussão é, na verdade, um debate metodológico sobre o Direito, ou melhor, um debate ontológico onde se trata de definir a relação entre a esfera jurídica e a vida".

5 Nos termos de Tarde, ainda que toda possessão seja unilateral ela não exclui, em toda a sua extensão, o momento de reciprocidade que se estabelece numa determinada relação. A possessão unilateral é a forma da relação extrassocial (Tarde, 2007, p. 115), isto é, aquela que se impõe entre uma mônada (ou um indivíduo) e um conjunto indiscernível de outras (ou uma associação realizada em um grau de repetições e diferenças no qual ele não pode penetrar). É esse momento de reciprocidade que ocorre mesmo nas possessões unilaterais, aliás, a condição da compreensão da realidade. 


\section{Referências}

ALMEIDA, Mauro. Guerras culturais e relativismo cultural. Revista Brasileira Ciências Sociais, [S.l.], v. 14, n. 41, p. 5-14, 1999.

BARRETO FILHO, Henyo Trindade. Disciplinando a diversidade cultural: uma perspectiva antropológica sobre a Portaria 14. In: LIMA, Antônio Carlos de Souza; BARRETO FILHO, Henyo Trindade (org.). Antropologia e identificação: os antropólogos e a definição de terras indígenas no Brasil, 1977-2002. Rio de Janeiro: Contra Capa Livraria, 2005. p. 119-135.

BEVILAQUA, Ciméa Barbato. Chimpanzés em juízo: pessoas, coisas e diferenças. Horizontes Antropológicos, Porto Alegre, v. 17, n. 35, p. 65-102, 201 1. Disponível em: http://www.scielo.br/scielo.php?script=sci arttext\&pid $=$ S0104-718320110001000038lng $=$ enfnrm $=$ iso. Acesso em: 26 jul. 2017.

BONILLA, Oiara; CAPIBERIBE, Artionka. A ocupação do Congresso: contra o quê lutam os índios?. Revista de

Estudos Avançados, [on-line], v. 29, n. 83, p. 293-313, 2015.

Disponível em: http://www.scielo.br/scielo.php?script =sci arttext\&pid $=$ S0103401420150001002938lng $=$ enfnrm $=\overline{\text { iso. }}$. Acesso em: 28 jul. 2017.

BRASIL. Constituição da República Federativa do Brasil de 1988. Brasília, DF: Senado Federal, 1988.

BRASIL. RE n. 44.585-MT. Supremo Tribunal Federal. Relator: Ministro Ribeiro da Costa. Recorrente: Presidente da Assembleia Legislativa do Estado de Mato Grosso. Publicado no Diário da Justiça de 12/10/1961, p. 02239. Data do julgamento: 30/08/1961.

BRASIL. Petição n. 3.388-4-RR. Supremo Tribunal Federal. Relator: Ministro Carlos A. Britto. Requerente: Augusto Affonso Botelho Neto. 2007. Disponível em: http://www.stf.jus.br/arquivo/cms/noticianoticiastf/ anexo/pet3388ma.pdf. Acesso em: 12 ago. 2017.

BRASIL. Relatório final da Comissão Parlamentar de Inquérito Funai-Incra 2. Câmara dos Deputados. Presidente da Comissão: Dep. Alceu Moreira. Relator: Dep. Nilson Leitão. [2017]. Disponível em: http://www.camara.leg.br/internet/comissoes/comissoes-especiais/CPI/ RELATÓRIO\%20CPI\%20FUNAI-INCRA\%202.pdf. Acesso em: 14 set. 2017.

CARNEIRO DA CUNHA, Manuela. Imagens de Índios do Brasil: O Século XVI. Revista de Estudos Avançados, São Paulo, vol. 4, n. 10, 1990. Disponível em: http://www.scielo.br/scielo.php?script =sci arttextEpid =S010340141990000300005\&lang =pt. Acesso em: 10 ago. 2017. 
CARNEIRO DA CUNHA, Manuela. Índios no Brasil: história, direitos e cidadania. São Paulo: Claro Enigma, 2012.

COELHO DE SOUZA et al. T/terras indígenas e territórios conceituais: incursões etnográficas e controvérsias públicas - projeto de pesquisa. Entreterras, [S.l.], v. 1, n. 1, p. 4-35, 2017. Disponível em: https://drive. google.com/file/d/0B07ktXK0lzo0eVJkV0tPcm5pbXc/view. Acesso em: 30 jul. 2017.

FAUSTO, Carlos. Território e Contraditório: antropólogos, índios e poderes de estado. Comunicação apresentada no SEMINÁRIO INDIGENISMO: FIM DE SÉCULO, no Departamento de Antropologia de UnB, em 22 de maio de 1998. Mimeo.

GALLOIS, Dominique Tilkin. Terras ocupadas? Territórios?

Territorialidades? In: RICARDO, F. (org.). Terras Indígenas \& Unidades de Conservação da natureza: o desafio das sobreposições. São Paulo: Instituto Socioambiental, 2004. p. 372-383.

HERMITTE, Marie-Angèle. Le droit est un autre monde. Enquête - Anthropologie, Histoire, Sociologie, [S.l.], n. 7, p. 17-37, 1999. Disponível em: http://enquete.revues.org/1553. Acesso em: 18 jul. 2017. INGOLD, Tim. Being alive: essays on movement, knowledge and description. New York: Routledge, 2011.

LACERDA, Rosane Freire. Os Povos Indígenas e a Constituinte: 1987/1988. Brasília: Cimi, 2008.

MALPAS, J. Place and Experience. Cambridge University Press, Cambridge, 1999.

MARÉS, Frederico. Comentário aos artigos 231 e 232 da CF-88. In: CANOTILHO, J. J. Gomes; MENDES, Gilmar F.; SARLET, Ingo W. (coord.). Comentários à Constituição do Brasil. São Paulo: Saraiva/Almedina, 2013. p. 2.147-2.158.

MIRAS, Julia Trujillo. De terra(s) indígena(s) à Terra Indígena: o caso da demarcação Krĩkati. 2015. 140p. Dissertação (Mestrado) - Programa de Pós-Graduação em Antropologia Social/Universidade de Brasília, Brasília, 2015.

MOLINA, Luísa Pontes. 2017. Terra, luta, vida: autodemarcações indígenas e afirmação da diferença. 2017. 205p. Dissertação (Mestrado) - Programa de Pós-Graduação em Antropologia Social/Universidade de Brasília, 2017.

NODARI, Alexandre. A posse contra a propriedade: pedra de toque do Direito Antropofágico. 2007. 168p. Dissertação (Mestrado) - Universidade Federal de Santa Catarina, Florianópolis, 2007. 
NODARI, Alexandre. Recipropriedade: ocupação e cuidado com a T/terra. Florianópolis: Seminário Antropologias da T/terra. 2016. Mimeo.

NUNES, Eduardo. Lévy-Bruhl no país dos Karajá. (No prelo).

OLIVEIRA FILHO, João Pacheco. Os instrumentos de bordo: expectativas e possibilidades do trabalho do antropólogo em laudos periciais. In: SILVA, Orlando Sampaio; LUZ, Lídia; HELM, Cecília Maria Vieira. A perícia antropológica em processos judiciais. Florianópolis: EdUFSC, 1994. p. $115-136$.

OTERO DOS SANTOS, Júlia. Andar sobre a terra: constituição de lugares, coletivos e espaços-tempos entre os Karo-Arara. (No prelo). PONTES, Jaqueliny. Mundo está de olho na Floresta Amazônica, alerta Davi Kopenawa. [2015]. Disponível em: https://acervo. racismoambiental.net.br/2015/04/20/mundo-esta-de-olho-na-florestaamazonica-alerta-davi-kopenawa/. Acesso em: 15 ago. 2017.

POTTAGE, R. A.; MUNDY, M. (ed.). Law, anthropology, and the constitution of the social: making persons and things. Cambridge, UK: Cambridge University Press, 2004. p. 1-39.

RILES, Annelise. The Empty Place: Legal Formalities and the Cultural State. [2002]. Disponível em: http://ssrn.com/abstract $=302156$. Acesso em: 10 ago. 2017.

RILES, Annelise. Property as Legal Knowledge: Means and Ends. Journal of the Royal Anthropological Institute, [S.l.], v. 10, n. 4, p. 775-795, 2004.

SILVA, José Afonso da. 2008. Curso de Direito Constitucional Positivo. 31. ed. São Paulo: Malheiros, 2008.

SOARES-PINTO, Nicole. De coexistências: sobre a constituição de lugares djeoromitxi. Revisa R@u de Antropologia, São Carlos, SP, 2017.

STENGERS, I. Cosmopolitics I. Minneapolis: University of Minnesota Press, 2010.

TARDE, Gabriel. Monadologia e sociologia: e outros ensaios. Tradução de Paulo Neves. Organização de Eduardo Viana Vargas. São Paulo: Cosac Naify, 2007.

TEUBNER, Gunther. Contracting Worlds: The Many Autonomies of Private Law. Social e Legal Studies, [S.l.], v. 9, p. 399-417, 2000.

THOMAS, Yan. Présentation. Annales Histoire, Sciences Sociales, [S.l.], Ano 57, n. 6, p. 1.425-1.428, 2002. 
UNESCO - Organização das Nações Unidas para a Ciência, a Educação e a Cultura. Declaração das Nações Unidas sobre os Povos Indígenas: perguntas e respostas. 2. ed. Rio de Janeiro: UNIC; Brasília: UNESCO, 2009.

Recebido em 05/1 1/2017

Aceito em 07/04/2018

\section{Andressa Lewandowski}

Doutora em Antropologia Social, Professora da Universidade da Integração Internacional da Lusofonia Afro-brasileira

E-mail: andressapr@gmail.com 